\title{
Left atrial volume, congestive heart failure, and obesity are associated with extent of left atrial fibrosis by late gadolinium enhancement
}

\author{
Karl Grunseich*, Bethlehem Mekonnen, Lauren A Simprini, Hamid Mojibian, Mark Marieb, Gourg Atteya, \\ Daniel Cornfeld, Dana C Peters
}

From 18th Annual SCMR Scientific Sessions

Nice, France. 4-7 February 2015

\section{Background}

The cardiovascular MRI late gadolinium enhancement (LGE) sequence has developed as a tool to evaluate fibrosis in the atrial walls. LA remodelling and fibrosis is theorized to precede the onset of and to increase with the persistence of AF. Pathological studies have demonstrated that other cardiac diseases are associated with LA fibrosis regardless of the presence of AF. Identifying conditions associated with LA LGE in the general population could be important for risk stratification of atrial fibrosis and AF development in patients with such comorbidities. This study aims to identify common clinical conditions associated with greater LA LGE.

\section{Methods}

We retrospectively identified and reviewed the medical records of 181 consecutive subjects imaged with cardiac MRI on a Siemens 1.5T from 2012 to 2013 at our institution. Subjects with age less than 21, prior ablation, or prior sternotomy were excluded. Of the remaining 148 subjects, those were excluded who did not have a 3D LGE sequence or if it was not interpretable. LGE in the LA was described by its presence in 18 locations, resulting in a semi-quantitative score. Measurements of the LA end diastolic volume (LAEDV) and LA end systolic volume were approximated by biplane area-length and used to quantitate LA ejection fraction (EF). Clinical conditions of hypertension, hyperlipidemia, congestive heart failure (CHF), diabetes, obesity, AF, other cardiac disease, and smoking status were identified. Patient medication usage was also determined. Data were

Yale University School of Medicine, New Haven, CT, USA analyzed using linear regression, t-tests, and analysis of covariance using JMP v10 (SAS Institute Cary NC).

\section{Results}

Subject ( $\mathrm{N}=88$ ) characteristics consisted of $41 \%$ female, mean age 50.8 \pm 14.8 , BMI $28.8 \pm 6.4$ (Figure 1). LA LGE was associated with LAEDV index in subjects both with and without $\operatorname{AF}\left(\mathrm{r}^{2}=0.192, \mathrm{r}^{2}=0.226\right.$ respectively, $\mathrm{p}<0.05$; Figure 2). Analysis of covariance demonstrated a

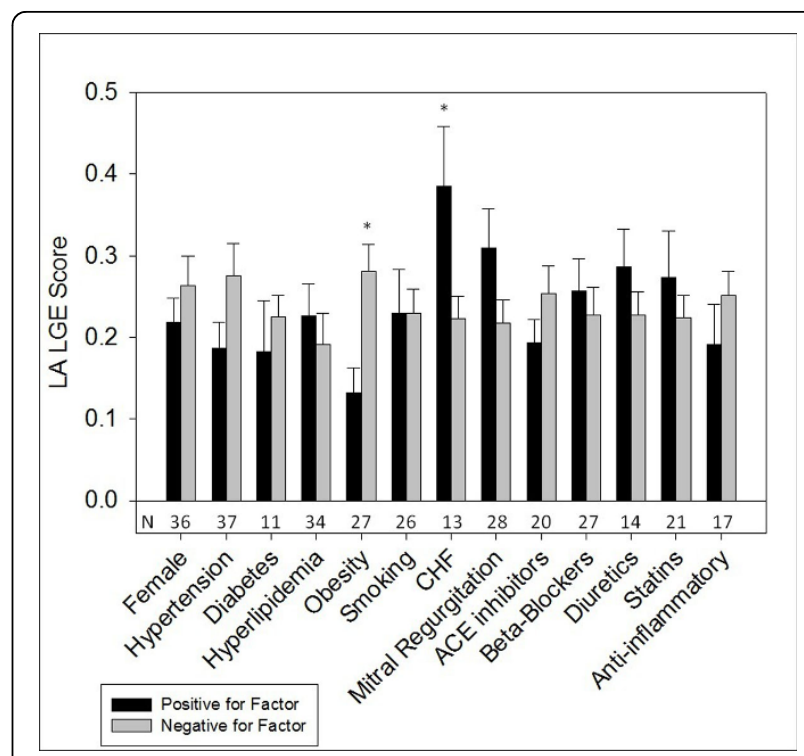

Figure 1 Clinical factors and association with LA LGE score. Obese subjects had lower LA LGE score while subjects with congestive heart failure had higher LA LGE score $(p<0.05)$. Number under bar indicates subjects positive for each factor. Values are mean + S.E. Overall $\mathrm{N}=88$. 

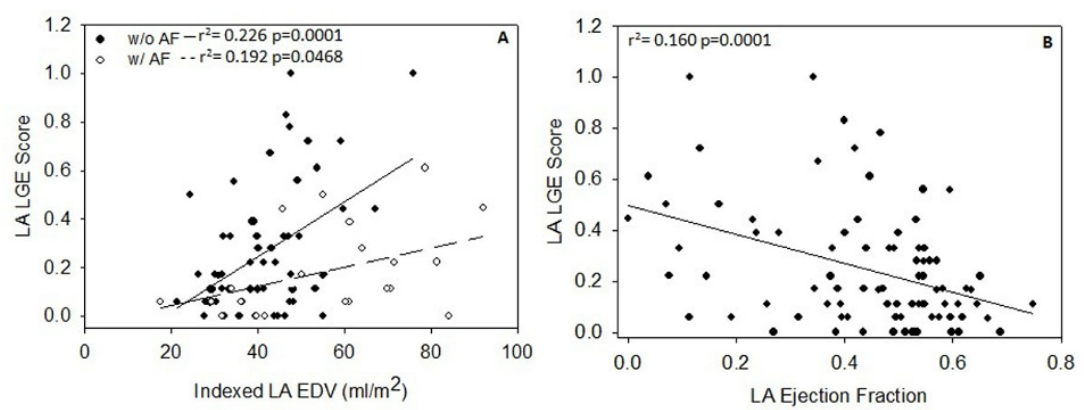

Figure 2 Left atrial end diastolic volume (A) and ejection fraction (B) are mildly associated with left atrial LGE.

steeper relationship in patients without $\mathrm{AF}(\mathrm{p}=0.039)$. Decreased LA EF was associated with increased LA LGE $\left(r^{2}=0.16 p<0.001\right)$. After accounting for the effects of LAEDV, subjects with CHF had higher LA LGE scores $(\mathrm{p}=0.039)$ while obese subjects had lower LA LGE scores $(\mathrm{p}=0.005)$. Hypertension, hyperlipidemia, diabetes, age, sex, medication usage, and smoking were not significantly associated with differences in LA LGE.

\section{Conclusions}

Among this subject cohort, the strongest predictor of LA LGE was LA EDV. Additionally, LA EF showed an association with LA LGE. Atrial fibrosis is thought to develop with many cardiac diseases. Accordingly, we found higher LA LGE scores in subjects diagnosed with CHF after accounting for LA volumes. This suggests that the higher LA LGE in CHF subjects was not due to LA volume increases alone. Interestingly, obese patients had lower LA LGE score than non-obese patients. It is unclear whether this is related to a true protective effect of obesity and requires future investigation.

\section{Funding}

This work was partly funded by NHLBI R21 HL 098573.
doi:10.1186/1532-429X-17-S1-P368

Cite this article as: Grunseich et al:: Left atrial volume, congestive heart failure, and obesity are associated with extent of left atrial fibrosis by late gadolinium enhancement. Journal of Cardiovascular Magnetic Resonance 2015 17(Suppl 1):P368.
Submit your next manuscript to BioMed Central and take full advantage of:

- Convenient online submission

- Thorough peer review

- No space constraints or color figure charges

- Immediate publication on acceptance

- Inclusion in PubMed, CAS, Scopus and Google Scholar

- Research which is freely available for redistribution

Submit your manuscript at www.biomedcentral.com/submit 